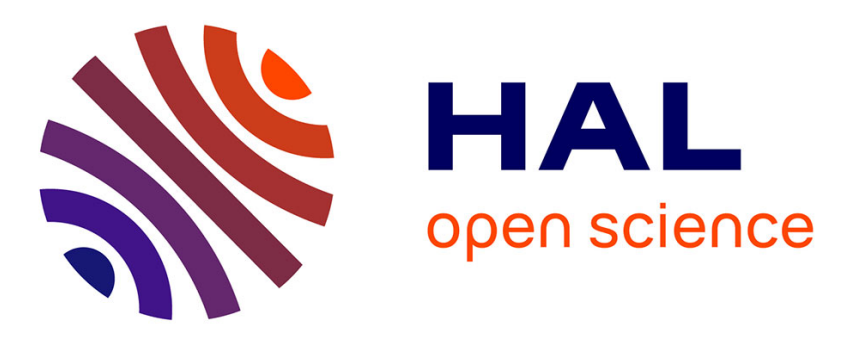

\title{
Information management in the logistics service industry: A strategic response to the re-integration of logistical activities
}

Nathalie Fabbe-Costes

\section{- To cite this version:}

Nathalie Fabbe-Costes. Information management in the logistics service industry: A strategic response to the re-integration of logistical activities. Transport Logistics, 1997, 1 (2), pp.115-127. 10.1163/156857097300151642 . hal-01297064

\section{HAL Id: hal-01297064 \\ https://hal.science/hal-01297064}

Submitted on 2 Apr 2016

HAL is a multi-disciplinary open access archive for the deposit and dissemination of scientific research documents, whether they are published or not. The documents may come from teaching and research institutions in France or abroad, or from public or private research centers.
L'archive ouverte pluridisciplinaire HAL, est destinée au dépôt et à la diffusion de documents scientifiques de niveau recherche, publiés ou non, émanant des établissements d'enseignement et de recherche français ou étrangers, des laboratoires publics ou privés. 


\title{
Information management in the logistics service industry : A strategic response to the re-integration of logistical activities
}

\author{
NATHALIE FABBE-COSTES \\ Mediterranean University - Aix-Marseille II, Centre de REcherche sur le Transport et la \\ LOGistique, France
}

CRET-LOG

Avenue Gaston Berger

13625 AIX-en-Provence Cedex 1

France

Tél CRET-LOG : 33-4-42-93-90-33 - Fax CRET-LOG: 33-4-42-26-17-32

Personal fax : 33-4-91-41-03-82 - E-mail : nfc@ romarin.univ-aix.fr

\begin{abstract}
The logistics services market has evolved over the last 30 years and the LSPs has been expanding their role in the logistics chains, but shippers benefit from considerable negotiating power and constantly evaluate the relative advantages of subcontracting or performing the work themselves in-house. The threat that shippers may reintegrate logistics activities, which has always existed, has become more acute in Europe over the past two years.

The management of information, expertise and knowledge is according to us a major strategical factor for LSPs to avert a major swing back to in-house operation. Information management is vital as shippers need to exert tight control over their logistical operations and to maintain their expertise in this area. Skills management is important for LSPs either to differentiate their services and/or to develop complex or innovative logistics services.

The management of LSPs, like that of all businesses, depends on three inter-related dimensions of competence : action, expertise and knowledge; and the need for effective collection, communication and processing of information exists on each dimension. In managing information, LSPs must establish congruence with the shippers' systems that can be achieved on one or more of the dimensions. This highlights the importance of the design of LICS and the supporting information and communication technologies to the furure competitiveness of LSPs. Close integration of the information systems of LSPs and shippers will be essential to maintain the mutual trust necessary for long term relationship and to maintain their ability to adapt to the changing business environment.
\end{abstract}

Keywords : Logistics management; logistics information systems; logistics service providers; reintegration of logistical activities, information and skills management. 


\section{INTRODUCTION}

Nobody would contest that since the beginning of the 1980s, logistics has become a real industry and that logistics suppliers have been playing an ever increasing role within logistics chains. This evolution had led to the development of partnerships between shippers and logistics service providers (LSPs) and alliances between LSPs [1]. Most of the research on this suject assumes that the general trend towards greater subcontracting of logistics activities will continue. Interviews recently undertaken accross Europe in association with CELO and McKinsey [2] have suggested that logistics managers in some major corporations are considering reversing this trend and reintegrating logistical activities which they currently contract out. They also presented arguments to justify such action.

This finding has prompted further research involving a new programme of interviews with logistics managers, designed to provide answers to the following questions :

(1) Why should shippers be tempted to reintegrate certain logistics activities?

(2) What kinds of activities are affected?

(3) What actions might LSPs take to counter the return to in-house operations?

In an earlier paper [3], presenting the preliminary results of this research, three strategies that LSPs might adopt were identified: (1) building a coherent and homogeneous 'portfolio of strategic logistical services'; (2) improve the management of three inter-related competencies (action, expertise and knowledge); (3) under certain circumstances, establish 'partnerships' with clients and/or 'alliances' with other LSPs.

In this paper, we explore in greater depth how LSPs can use the management of information and expertise to adress the threat to their business posed by shippers wishing to reinternalize logistics functions.

The paper begins by examining the main characteristics of the logistics supply industry and the reasons why shippers are expressing a desire to take some of their logistics operations back in-house. Later sections focus on the strategic importance for logistics suppliers of managing information at the action, expertise and knowledge levels.

\section{CHARACTERISTICS OF THE LOGISTICS SERVICES INDUSTRY}

\subsection{Division of responsibility for logistical activities}

The logistics services market has evolved over the last 30 years and during this period it has been contested by different types of organization. In addition to the LSPs which provide a third-party logistics service, many manufacturers and retailers have retained direct involvement in logistics, often using it as an extension of their core business. In some cases, the logistical activities of these different organizations are in competition, in others they are 
essentially complementary. The aspiration to extend their responsibility for logistical activities can be broadly summarized as follows.

Manufacturers often control their inbound logistics (supplies to the manufacturing plant) and their outbound logistics (supplies to customers or retail networks). At a time when stocks are being reduced, service levels improved and 'just-in-time' methods becoming more prevalent, manufacturers see powerful and structured logistics as a way of ensuring efficiency, reliability and durability.

Retailers whose main concern is the management of sales outlets have, in many cases, seized control of the inward flow of supplies. This enables them, among other things, to regulate deliveries and reduce the level of inventory. The ever-increasing size and number of their retail outlets plus their purchasing power allow them to take full advantage of the economies of scale in transport and storage. By integrating logistical activities, retailers can improve their productivity and increase the reliability of shop replenishment.

Logistics service providers, acting as an interface between the logistics systems of both manufacturers and retailers, tend to exploit this potentially favourable situation by building up a 'neutral' multi-manufacturing and/or multi-retailer logistical service, able to operate shared distribution operations. In theory, the logistics supplier is then in a strong position to co-ordinate flows. A significant proportion of third party logistics services are, nevertheless, provided on a dedicated contract basis.

The same logistics activity can be performed by any one of the three partners in the logistics chain, depending on how far they choose to extend their original activity. It is not possible, on an a priori basis, to determine the optimal allocation of responsibility for logistics between the three agencies. Nevertheless, the LSPs has been expanding their role in the logistics chains, promoting themselves as offering greater specialization and professionalism.

\subsection{Evolution and characteristics of the logistics supply industry}

In France and several other European countries, the logistics supply industry has developed through four main stages.

Stage 1. The 1970s saw the arrival of the first generation of logistics suppliers resulting, in some cases, from some manufacturers hiving-off their in-house distribution operations. These companies undoubtedly pioneered the development of logistics skills, initially in the areas of warehousing and forwarding. Many subcontracted their transport needs to small hauliers.

Stage 2. Logistics know-how gradually spread to road transport companies many of which offered only regional coverage. They took advantage of this opportunity to diversify, by supplementing their original transport services with other services. National networks began to appear and consolidated the services of several regional companies. These 
operators, which, in many cases, became logistics suppliers to large manufacturers, combined their respective flows to provide consignee groupages, mainly for supermarkets. This period also saw some LSPs being 'spun-out' of retail organizations, which thereafter not only serviced the logistical needs of the parent company but also those of wholesale affiliated.

Stage 3. At the end of the 1980s the demand for third-party logistical services was extreme buoyant. Many LSPs began to specialize and provide state-of-the-art expertise in particular types of logistic services. Some catered for the needs of large-scale retail companies for which they set up customized solutions. Others, taking advantage of the know-how they had acquired at higher levels in the supply chain concentrated on supplying industrial plants often on a just-in-time basis. They could pre-assemble components to deliver a complete module to an assembly plant. Some of these LSPs focused their attention on the upper reaches of logistics chains and became involved primarily in the movementand storage of spare parts. Finally, some wholesalers began to provide 'pure' third-party logistic services (e.g. pharmaceutical products wholesalers), and a number of them even found themselves devoting equal time to logistics services and their traditional wholesale activities.

Stage 4. The most recent phase of this progression has been the quest for new markets. This is well exemplified by the growth of third-party reverse logistics services in the collection and recycling of waste.

The logistics services industry today appears to be particularly complex and segmented into several distinct sectors. The wide differences between LSPs reflect their differing origins and subsequent diversification and specialization. They offer broad range of experience, management culture, knowledge and know-how. The industry is undoubtedly maturing, though is still highly fragmented. This fragmentation makes the industry intensively competitive. Some LSPs that at the outset operated in separate markets segments are now to a certain extent in competition. 'Hierarchism' has also developed within the industry, with the 'leading' logistics suppliers organizing the sections of the chain under their control and subcontracting the activities they consider less profitable to smaller operators that usually have less room to manoeuvre. Where market niches exist they tend to be risky and temporary.

The high degree of fragmentation in the industry is largely a consequence of the fact that there are few barriers to entry. These barriers are higher, however, where the service is more complex and capital-intensive, where there is a rapid rate of innovation or where firms are required to provide wide geographical coverage. Where barriers are low, services are usually substituable (e.g., between modes of transport) and shippers can often switch traffic between carriers at minimal cost. As the slightest failure may rapidly prove disastrous, the position of the LSPs operating in 'spot' markets is always precarious.

Shippers benefit from considerable negotiating power, and their management expertise is often greater than that of the LSPs on whom they impose their logistics solutions. They are 
also loath to commit themselves over long periods and prefer short-term contracts (especially in France). Their experience of controlling logistics activities encourages them constantly to evaluate the relative advantages of subcontracting or performing the work themselves in-house.

This industry, which was able to find a certain equilibrium at the end of the 1980s, is again restructuring. Some factors threatening to upset the existing balance are inherent in the logistics supply industry, in particular the increased competition and the hierarchical organization within the industry. Other more significant factors are linked to the development of shipper strategy, in particular the threat that shippers may reintegrate logistics activities. This threat, which has always existed, has become more acute in Europe over the past two years even though it is still only psychological and not yet manifest in company behaviour.

\section{POTENTIAL REINTEGRATION OF LOGISTICS OPERATIONS}

\subsection{The strategic nature of logistics operations for shippers}

According to a study carried out in France by BIPE [4] 'a product spends $15 \%$ of its time being manufactured and the remaining $85 \%$ in flow operations (storage, transfer, transport, etc.).... and the cost of logistics can be estimated at approximately $12 \%$ of turnover'. Controlling these logistics times and costs is a strategic challenge for shippers. The impact that logistics has on a company is measured not only in cost terms but also, to an ever increasing extent, by the quality of the logistics service. The 'logistics service' is anintegral part of firms' market offering and strongly influences their competitiveness. Two surveys carried out by the American consultancy firm A.T. Kearney show there have been improvements in the quality of logistic services in large European companies: an average reduction of $31 \%$ of service failures between 1987 and 1992 and an expected reduction of $60 \%$ between 1992 and 1997. It also has been found that logistics costs are increasing as a proportion of value added $[5,6]$.

This raises a difficult question. Should companies continue to subcontract to take advantage of the skills of a service industry that is becoming increasingly professional or should they reintegrate (or develop) at least partly an activity that has such an important influence on company performance? According to the study carried out by BIPE, $85 \%$ of manufacturing companies in France use logistics subcontractors, the cost of subcontracting representing $55 \%$ of logistics costs.

One firm which has decided to retain a large direct involvment in logistics is PhilipsEclairage. It decided to make a substantial capital investment (several hundred million francs) in a highly automated warehouse. It supplies customers (70\% wholesalers, $15 \%$ supermarkets, $15 \%$ fitters) located in France and in certain areas of bordering countries with 
central supply facilities. Philips-Eclairage has managed to enhance its responsiveness and reduce delivery time (from a maximum 72 to $48 \mathrm{~h}$ ). Although still heavily engaged in warehousing operations, the firm contracts out the final delivery of its products.

\subsection{Possible motives for the reintegration of logistics functions}

Considering the importance of the logistics service, it seems logical that shippers should weigh up the advantages of maintaining their subcontractors or reintegrating all or part of their subcontracted operations. Let us consider the motives for reintegration in greater detail.

The main temptation for shippers to reintegrate logistics operations is often the desire to assert direct control over the cost and quality of these activities. When activities are subcontracted, this control is linked directly to knowing how to get things done. In view of the rapid developments made in the logistics profession, a number of shippers, that have relinquished the management of logistical activities, are concerned that they are notupdating their expertise in this area and becoming uncertain about the net benefits of continuing to contract out their logistics. They are tempted to reintegrate, at least in part, some logistics activities if only to reacquaint themselves and establish a firmer basis for evaluating logistical performance. They are even prepared to subcontract this work out again at alater stage, applying new criteria.

An example of this is J. Sainsbury, the British supermaket chain, which uses contractors to operate twenty of their twenty-four distribution centers. As stated by Quarmby, the former Managing Director of the company, 'there are two reasons for continuing to own these four centers. Firstly we can continue to obtain detailed knowledge of this profession and experience in managing operational tasks. Secondly, it provides us with an opportunity to try out new techniques and new methods without having to persuade a subcontractor to perform what could for him prove a risky investment'.

Another motive that shippers might have for reintegrating logistics operations is to reduce the strategic risk they take when they entrust to logistics suppliers activities from which they gain a significant competitive advantage. The level of risk is determined by the operating reliability of the logistics supplier which, in turn, influences the loyalty of the shipper's customers. The level of risk is also determined by the strategic 'discretion' (i.e. ability to withhold from competitors the same services and/or not disclose the relevant know-how) that influences the ability of the other firms to compete. The LSP's reliability and discretion are key factors affecting the sustainability of the shipper's competitive advantage.

Another important factor when choosing between subcontracting, integration or reintegration, is the level of investment required to perform logistics activities, and the ability of companies to make an adequate return on these investments before they are rendered obsolete by new logistics developments. For quite some time, this factor gavemanufacturers and retailers a good reason to reduce their direct involvement in logistics, particularly for 
transport. In restructuring their logistical operations at a European scale, some manufacturers are now finding that the economies of scale they can achieve in consolidating their operations are making direct investment in logistical facilities more attractive. They can show a healthy return on these large scale investments, particularly as their size and status enables them to borrow from financial institutions at somewhat lower rates than those obtained by logistics suppliers.

The final factor influencing the decision to reintegrate logistics activities is that of personnel. Since the 1980s, the increasing complexity of logistics facilities has been combined with rapid developments in logistics information and communication systems (LICS). At the same time, the qualifications of logistics staff have risen, particularly in warehousing, reflecting the development of more advanced handling and storage technologies. The differences in technical skills required by manufacturing, retailing and logistics activities are lessening, which makes manufacturing and retailing companies more inclined to reintegrate these operations. Moreover, the management of logistics personnel is no longer a hindrance to the reintegration of these activities, as the mechanization of warehouses has reduced the need to employ large numbers of poorly qualified workers. However, this is only feasible for companies handling with sufficient volumes to justify investment in highly mechanized systems, and for companies with financial clout, which is often not the case for LSPs.

\subsection{Logistical operations most likely to be reintegrated}

Discussions with European shippers have revealed that logistics operations are more likely to be reintegration than others. The following examples were given. They are neither mutually exclusive nor presented in order of importance. Shippers only envisage reintegration for :

- operations that directly concern customer services. The more an operation affects the shipper's customer, the more it is seen to be sensitive. This confirms that logistics has become a strategic marketing element for many manufacturing and retailing companies.

- operations that require the handling of information thought to be 'strategic' (usually pertaining to customers and/or cost structure).

- operations considered to be 'critical' in the shipper's logistics process (i.e. in terms of their service and/or logistics costs), or more precisely, operations in which security is more important than flexibility.

- operations that do not require a large amount of new investment, particularly those for which physical or information systems have already been set up within the company.

- operations that offer a rapid rate of return on investment in logistics assets.

- operations that require highly specific investment and which LSPs, especially those providing mainly shared-user services, find difficult to run profitably. 
- operations that do not require staff with a different culture than that already prevalent in the company.

- operations that require highly specific skills, not available from a logistics supplier.

It can be seen that the increasing need for either dedicated investments and specialistskills can act both to encourage and discourage reintegration. Where these skills are innovative and/or closely tailored to a shippers' operations, a move back to in-house operation is favoured. Other shippers can obtain the specialist skills they require from existing LSPs and hence are more inclined to continue contracting out their operations.

The decision to continue subcontracting or, on the contrary, to reintegrate logistics activities is in any event contingent. First it depends on the situation of the logistics supply industry at the time when the issue arises. It also depends on the shipper's perception of the relative risks and benefits of the two options. Moreover, this dilemma usually only arises when a shipper is conducting a strategic review of its logistical system. Reinternalization can then occur as part of a wider restructuring of a firm's logistics. Van Laarhoven [7] indicates that $43 \%$ of the fifty European LSP shipper contracts that he examined in 1994 were renegotiated in that year. The result of the renegotiations were that $82 \%$ of shippersrenewed the contract with the same LSP, 9\% changed LSP, and 9\% decided to bring logistics back in-house.

The reintegrating of these activities poses an obvious threat to LSPs. The threat is all the more important because it is the larger companies that are today considering this option. They demonstrate that, where logistics is concerned, no decision is ever permanent. Thefact that shippers do not have logistics infrastructure currently in place does not guarantee a future role for LSPs. Shippers, in particular manufacturing companies, often have the financial resources required to make the necessary investments and, in many cases, either have or can acquire personnel to run their logistical operations.

While there may be an increase in the proportion of logistics activity performed in-house, much logistics work will continue to be contracted out, particularly in the case of transport operations. Nevertheless, the potential for reintegration is now great enough to requireLSPs to give serious thought to how they might counter this trend. Indeed the likehood of this trend becoming established will partly depend on the measures that LSPs adopt. It is important, therefore, that they consider what strategic actions will be needed to avert a major swing back to in-house operation. Our purpose here is not to formulate contingency plans for LSPs, but to examine the factors that are likely to figure prominently in their future strategies, namely the management of information, expertise and knowledge. 


\section{MANAGEMENT OF INFORMATION, EXPERTISE AND KNOWLEDGE}

\subsection{Why should logistics suppliers focus on information and skills management?}

Because of competition in the logistics supply industry, shippers can now expect high standards when they contract out their logistical activities. Those standards relate both to physical operations and to the processing of information. The quality of information support is vital as shippers need to exert tight control over their logistical operations. Shippers also want detailed operational information to acquaint themselves with physical operations and maintain their expertise in this area. They are also interested in the security of an LSP's information system, because they do not want anyone to have access to information they consider commercially sensitive. Information management is also fundamental to efficient and reliable operation of LSP's business. Today, logistic organizations are working with much smaller safety stocks and, as a result, the effects of any disruption are rapidly transmitted along the logistics chain, often to the end customer. LSPs need an information and communication system directly linked to the physical flow of goods to forecast, plan, organise and follow the operational process and react against any disruption. Information management is thus a core activity and basic offering of LSPs.

In reviewing their strategies, logistics suppliers must also take account of two other factors : (1) the fiercer the competition, the greater will be the risk of shippers switching to another LSP, but the risk of shippers reintegrating logistical activities will be reduced; and (2) the greater the degree of expertise required, the greater will be the risk involved in providing the service, the higher will be the barriers to entry and hence the less intense will be the competition.

These factors highlight the importance of skills management for LSPs either to differentiate their services and/or to develop complex logistics services. To provideshippers with specialized or innovative services, logistics suppliers must be able to develop state-ofthe-art expertise, to convince shippers of their ability to provide a superior service and to avoid divulging the relevant know-how. Evolution of skills is another key factor toconsider. As specialist niches are risky and/or temporary, logistics suppliers must be able to adapt, or to develop, the expertise needed to exploit these niches very quickly.

Advances in technology are increasing the skills required to operate logistical systems. Skills management is thus crucial for LSPs who used to employ poorly qualified workers and experienced a relatively high turnover of staff. They need to enhance skills and learn how to consolidate experience if they want to perform sophisticated logistics operations.

Finally, it should be recognized that LSPs are becoming increasingly involved in consultancy and engineering services. In tendering for contracts they are often required to redesign a client's logistical system, providing an important value-added service, for which they are only compensated if they secure the contract. 


\subsection{Skills management}

Most of the research so far done on LSPs has concentrated on their mode of operation in terms of physical activites and information processing. Few attempts have been made to assess their overall competence. It is true that logistics suppliers are largely percieved through the logistics operations they perform for their contractors. These operations are the manifestation of higher-level organizational structures and processes.

The management of LSPs, like that of all businesses, depends on three inter-related dimensions of competence : action, expertise and knowledge. These provide LSPs with many ways of differentiating themselves from competitors and strategically positioning themselves vis-à-vis shippers :

Action relates to the way in which logistics services are actually performed. The nature of this physical service largely determines the entry barriers.

Expertise relates to all the resources directly associated with the Action, including methods, procedures, technologies and engineering. They strongly influence the quality, efficiency, durability and reliability of the logistics services and are a major source of competitive advantage.

Knowledge represents the highest level of abstraction in the management of LSPs. It is high-level information that must be collected and assimilated in the course of formulating strategy. It also incorporates the experience of senior managers and the general management culture of the business. To survive, an LSP must evolve and adapt. This can only be achieved by mobilising knowledge. It is important, therefore, that LSPs invest in high level management skills and in $\mathrm{R} \& \mathrm{D}$, and try to convert into knowledge everything that is experienced and perceived by people in the company.

Figure 1 illustrates the inter-relationship between the three dimensions of competence. An upward arrow signifies a demand from a lower dimension, while a downward arrow represents the effect of higher level knowledge on expertise and, in turn, operating procedures. A strengthening of an LSP's knowledge and expertise can result in the development of more complex services, which may be difficult for shippers to provide on an in-house basis. Unfortunately, however, many LSPs have been neglecting theirknowledge base. The restructuring of some of these businesses has resulted in the down-sizing of planning departments and loss of senior management staff with extensive knowledge of the industry.

Intrinsic to the development of more complex logistics services is information management $[8,9]$. The need for effective collection, communication and processing of information exists on each of the dimensions. Information management has therefore become a strategic factor for LSPs, especially those that wish to add value to the service offering. 


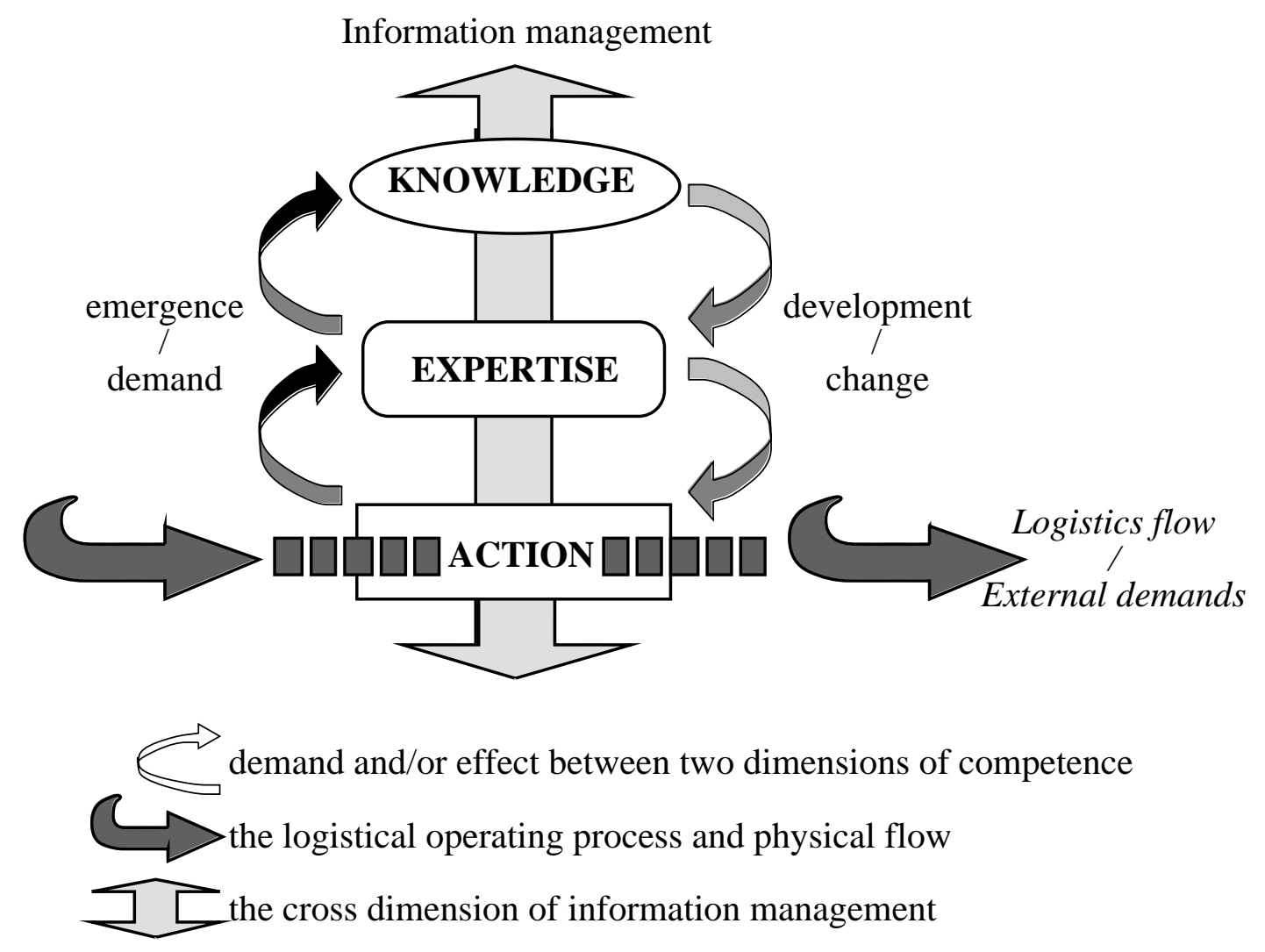

Figure 1. Inter-relationship between the three dimensions of competence

\subsection{Scope for improving information management}

Before examining information management in detail, it is necessary to consider how changes in relationship between LSPs and shippers are affecting the management of information in the logistics chain, particular for those logistics operations that have been identified as being 'sensitive' i.e. most likely to be re-integrated.

- Shippers are currently reducing the number of separate LSPs that they use. This is encouraging the formation of stronger inter-company links, particularly at the Actionlevel where day-to-day operations are performed and the operating staff on both sides are in close contact.

- When 'sensitive' logistics operations are subcontracted, shippers often seek a high degree of transparency to be able to audit and control the operations closely. This is conducive to the development of joint methods and procedures at the Expertise level [10].

- The development of closer, more open relationships results in greater willingness to pool information and knowledge. This can lead to the establishment of a joint frame of reference at the Knowledge level, a body of logistics knowledge common to both organizations. 
Despite the increasing temptation to reintegrate logistics operations examined above, all of these trends indicate that shippers are not against contracting out their logistics in principle, so long as information management enables them to control the logistics service and maintain their ability to adapt to the changing business environment.

For LSPs, information management offers a means of raising 'exit barriers' for shippers by increasing their substitution costs and creatinga means of adding value to their services. In managing information, LSPs must establish congruence with the shippers' systems. Depending on the degree of co-operation, this congruence can be achieved on one or more of the dimensions outlined above. LSPs must then develop LICS that are capable ofdealing with the three dimensions of competence and can be applied to all partners in the chain, in particular shippers.

In the Action dimension, LICS should help LSPs to improve the responsiveness of their operations. This is the basis of service performance, quality and reliability. At this level, LICS must capture and record all data produced by the logistics process (i.e. information directly generated at the operational level). The main objective is to build a complete database, if possible updated in real time, of what has happened and is happening in the logistics chain. It allows logistics suppliers to inform shippers of ongoing activities (to control operations and track physical flows) and to provide them with measures of the effectiveness and efficiency of the subcontracted activities.

LICS have been traditionally confined to the Action level. As explained above, however, this is no longer sufficient. LICS must also be designed as 'knowledge-based management systems'. At the Expertise level, LICS can help to formalize procedures and control systems, in line with the current move towards ISO 9002 certification. For this purpose, LICS can help to monitor logistics indicators, and can keep records of service failures on the part of both the LSP and the shipper. The analysis of these indices can lead to a significant improvement in existing systems. It also can help LSPs and their clients to co-operate in the development of new logistics expertise. At this level, LICS not only collect and record raw operating data but also are enriched with 'contextual information' that help managers to undertake statistical analysis and identify trends. By acting as a decision-support tool, LICS can help LSPs formulate 'behavioral rules' in their business, improve their procedures and knowledge, and detect trends in the business environment.

In addition to providing shippers with detailed operating data, LSPs can also help them understand the workings of the logistics system, updating their logistics know-how without tempting them to reinternalize the logistical function. This second level of LICS iscurrently developing, but there is still little sign of LICS being developed at the higher Knowledge level. At this level LICS could play three different roles.

The first role, which is quite widely recognised though insufficiently developed, is to furnish senior management with high-level strategic information, much of it relating to business trends and forecasts. 
The second is to assist the corporate learning process, helping firms assimilate the information and adapt their systems accordingly. A key element in logistics competence is its capacity to adapt the planning process to what is happening in the external business environment. If LICS provide a better (i.e. more adaptative, more evolutive) knowledgeabout logistics, it can help companies to find new management responses to changes in the business environment.

The third role is to capitalise on the collective knowledge on logistics within the organization. In theory, communication networks should be created internally to permit the assembly and exchange of all knowledge relating to the physical flow of goods. Once structured and distilled, much of this knowledge could be shared with shippers.

This highlights the importance of the design of LICS and the supporting information and communication technologies to the furure competitiveness of LSPs. Close integration of the information systems of LSPs and shippers will be essential to maintain the mutual trust upon which secure, long term relationship are built. The growth of Electronic Data Interchange (EDI) and Internet use is evidence that this integration is well underway. LSPs now need to build up their skills in the areas of information and communication design and in the associated technologies.

\section{CONCLUSIONS}

The logistics supply industry is currently maturing but remains relatively segmented. This competitive market is now facing a potentially threatening trend as major shippers that currently contract out their logistics activities are considering reintegrating some of them. Analysis of shippers' motives for reintegrating reveals that LSPs must recognize and react to this risk, even though the general principle of contracting out is still generally accepted. The extent to which the move back to in-house operations occurs will be directly linked to the attitudes and strategies that LSPs now adopt. Faced with this potential loss of business, LSPs must consider taking preventative measures. The main focus of these measures should be on information and skills management. We have identified three inter-related dimensions of competence in which information need to be more effectively managed : action, expertise and knowledge. LSPs should invest substantially in the development of information management at the upper two levels which have so far, in many firms, been relatively neglected. LSPs must develop LICS that deal with the three dimensions of competence. By doing so, they should be able to secure their long term position by addressing shippers current concerns about contracting out their logistics. 


\section{Acknowledgments}

I am grateful to Professor Jacques Colin of CRET-LOG for allowing me to use the results of our collective research in this paper.

I also thank Professor Alan C. McKinnon for his careful rereading of the paper.

\section{REFERENCES}

1. P. Van Laarhoven and G. Sharman, Logistics alliances: The European experience, The McKinsey Quarterly, Number 1, pp.39-49, (1994).

2. CELO and McKinsey, Operational Alliances in Logistics, working papers of the collective European Research by CELO and McKinsey. July (1993).

3. N. Fabbe-Costes and J. Colin, Strategies developed by logistics suppliers facing the temptation for shippers to reintegrate logistics operations, communication for the 7 th World Conference on Transport Research, organised by the IPACE. The University of New South Wales, Sydney, Australia (available in french and in english) (1995).

4. BIPE Conseil, La logistique dans l'industrie et la grande distribution en France, report February (1993).

5. AT Kearney, Logistics Productivity: The Competitive Edge in Europe. London (1987).

6. AT Kearney, Qualité et productivité logistique en Europe, étude réalisée pour l'European Logistics Association par le cabinet AT Kearney, éditée par Logistiques Magazine à l'occasion des 7èmes Assises Nationale de l'Économie Logistique. Paris (1992).

7. P. Van Laarhoven, The new logistics challenge : battle for value-added, in : Proceedings of the Premières rencontres Internationales de la Recherche en Logistique, pp. XIXXXXV. Marseille, France (1995).

8. N. Fabbe-Costes, Les systèmes d'information et de communication au coeur de la stratégie des prestataires logistiques?, in: Selected Proceedings of the 6th World Conference on Transport Research, Vol. I. pp. 319-330. Lyon, France (1992).

9. N. Fabbe-Costes, Logistic information and communication systems (LICS) are producing organization meanings, Proceedings of the International Conference on Systems, Man and Cybernetics, Vol. 5, pp. 300-305. Le Touquet, France (1993).

10. N. Fabbe-Costes and J. Colin, Formulating logistics strategy, in J. Cooper (ed.) Logistic and distribution planning: strategies for management, pp. 36-50, Kogan Page, London, (1994). 